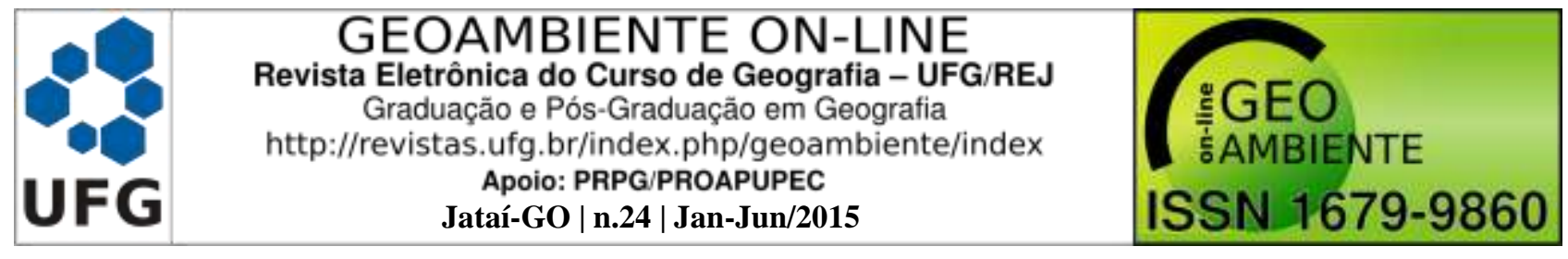

\title{
ASSOCIAÇÃO ENTRE A INCIDÊNCIA DE DENGUE E OS ELEMENTOS CLIMÁTICOS NA XVI RA DE JACAREPAGUÁ-RJ
}

Paulo Roberto de Souza Paiva ${ }^{1}$, Cássia Barreto Brandão ${ }^{2}$,Ricardo Augusto Calheiros de

\section{Miranda $^{3}$}

(1 - Universidade do Estado do Rio de Janeiro - UERJ, Bacharel em Geografia, paulopaiva.geo@hotmail.com; 2 - Universidade do Estado do Rio de Janeiro - UERJ, Doutoranda em Geografia, cassiabbgeo@gmail.com, 3 - Universidade do Estado do Rio de Janeiro - UERJ, Professor Titular de Climatologia, rmirandauerj@gmail.com)

RESUMO: Este estudo buscou compreender a influência dos elementos climatológicos sobre a incidência e a distribuição espacial dos casos de dengue na XVI Região Administrativa (RA) de Jacarepaguá, localizada no município do Rio de Janeiro, na qual compõe a Área de Planejamento 4 (AP 4). Esta área se configurou no período de 2001 a 2010 como aquela que deteve em média o maior número de casos da doença, onde se identificou dois picos com alto índice de dengue nos períodos de 2001/2002 e 2007/2008. Neste estudo foi estabelecida a correlação entre os elementos climáticos de temperatura e pluviosidade para a área com os casos de dengue, na qual se observou a sazonalidade bem definida, ou seja, a concentração dos casos foi percebida no período de verão a outono, não evidenciando, porém, a correlação com períodos epidêmicos do período, o que levou a refletir sobre os aspectos sociais e estruturais da malha urbana, bem como a evolução demográfica da área analisada, e os aspectos biológicos do vetor, Aedes Aegypti, que somados colocam uma luz sobre as indagações levantadas neste estudo.

Palavras-chave: dengue, clima, Jacarepaguá.

\section{ASSOCIATION BETWEEN THE INCIDENCE OF DENGUE AND THE CLIMATIC ELEMENTS IN THE XVI RA OF JACAREPAGUÁ-RJ}

ABSTRACT: This study seeks to understand the influence of the climatological elements on the incidence and the space distribution of the cases of dengue in 16th Administrative Region of Jacarepaguá, located in the city of RJ, which composes the Area of Planning 4. This area was considered in the period of 2001-2010 as the one that withheld the biggest number of 


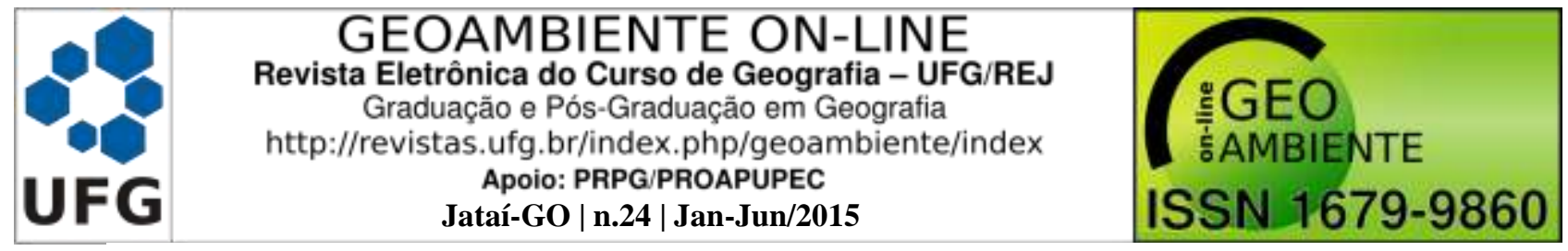

cases of the illness, when two peaks with a high index of the disease were identified in the period of 2001-2002, and 2007-2008. In this study, the correlation was established between the climatological elements of temperature and concentration of the cases was perceived in the period of summer, autumn, not evidencing, however, the correlation with epidemic periods, what led to reflect on the social and structural aspects of the urban mesh, as well as the demographic evolution of the analyzed area, and biological aspects of the vector, Aedes aegypti, which allowed to place light on the investigations raised in this study.

keywords: dengue, climate, Jacarepaguá

\section{ASOCIACIÓN ENTRE LA INCIDENCIA DE DENGUE Y LOS ELEMENTOS CLIMÁTICOS EN LA XVI RA DE JACAREPAGUÁ-RJ}

RESUMEN: Este estudio investigó la influencia de los factores climatológicos sobre la incidencia y la distribución espacial de los casos de dengue en la Región Administrativa XVI (RA) de Jacarepaguá, en el municipio de Rio de Janeiro, que compone el Área de Planificación 4 (AP 4). Esta zona se encuentra en el período 2001-2010 como un área que se identifica con medio la mayor cantidad de casos de la enfermedad, y que identificó dos picos con alto índice de dengue en los períodos 2001/2002 y 2007/2008. Este estudio establece la correlación entre los elementos climáticos de temperatura y precipitaciones en el área con los casos de dengue, en que se observó la bien definida sazonalidad, así, la concentración de los casos se observó en el período del verano al otoño, sin embargo , no evidenciando la correlación con los períodos epidémicos del período, lo que llevó a reflexionar sobre los aspectos sociales y estructurales del tejido urbano, así como la evolución demográfica de la zona analizada, y el vector biológico, Aedes aegypti, que en conjunto le puso una luz sobre las cuestiones planteadas en este estudio.

Palabras clave: el dengue, el clima, Jacarepaguá. Palabras clave: el dengue, el clima, Jacarepaguá.

\section{INTRODUÇÃO}

Segundo a FUNASA (2001), os primeiros relatos sobre dengue no mundo mencionam a Ilha de Java, em 1779, e, posteriormente, casos nas Américas, com epidemias no Caribe e nos Estados Unidos. No Brasil há relatos de surto de Dengue no Rio de Janeiro e Niterói, datados em 1923, no entanto, Teixeira et al., (1999) apontam que ocorriam epidemias de dengue desde 1846, nas cidades de São Paulo e Rio de Janeiro. 


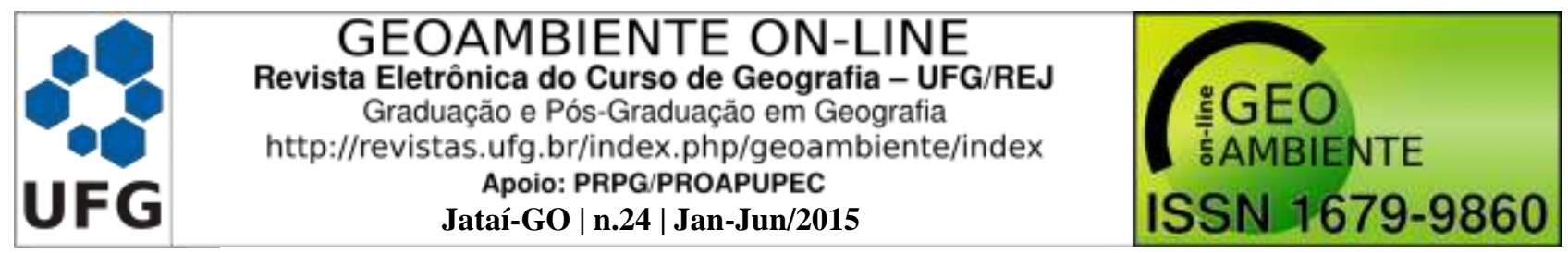

A Dengue no Brasil deve ultrapassar em breve a marca de 1 milhão de casos notificados por ano na próxima década. Esta é a tendência de crescimento, quando analisamos os dados de 2001 a 2010. A região do Brasil que detêm o maior número de casos notificados é o Sudeste, que na média de 2001 a 2010 deteve $43 \%$ dos casos notificados no Brasil (SMS/RJ 2014).

Ao observarmos os relatos históricos sobre a dengue, podemos perceber que as expansões das áreas de ocorrência no Brasil e nos países da zona tropical podem estar associadas ao crescimento da população e a expansão de áreas urbanas, que se desenvolvem de forma desordenada, ou seja, sem a devida estrutura de saneamento e planejamento urbano.

É importante destacar que, o fenômeno da "globalização", neste caso, nos referimos aquela iniciada no século XVI, a partir das grandes navegações marítimas como destacou Santos (2003), é imprescindível para relatar que a introdução do vetor, oriundo da África, possa ter sua provável chegada ao Brasil através de navios negreiros, onde encontrou condições favoráveis a sua proliferação, principalmente através das condições climáticas e áreas urbanas em franca expansão ( MENDONÇA et al, 2009).

A análise do espaço geográfico e os seus processos atuantes são de suma importância para compreender como a dinâmica atmosférica pode influenciar na incidência da Dengue em uma determinada área. Neste caso, as epidemias e a sua correlação com os elementos climatológicos, bem como aspectos sociais e naturais se relacionam, resultando em fenômenos cada vez mais recorrentes e complexos nos ambientes urbanos (SILVA et al,2007; KHORMI et al, 2011).

A Dengue é hoje uma das principais doenças vetoriais do mundo, tendo sua ocorrência predominantemente na zona tropical, ou seja, endêmica desta parte do Globo Terrestre (MONDINI et al, 2005). Muitas pesquisas e estudos em várias áreas do conhecimento são feitos anualmente para a compreensão dessa doença, onde muitos médicos, biólogos, geógrafos e químicos com seus respectivos objetos de pesquisa, têm utilizado o conhecimento para diminuir as consequências dessa doença do mundo, porém, muitos pesquisadores, incluindo geógrafos, negligenciam ou subestimam o papel do espaço geográfico no entendimento dessa doença, muitas vezes o interpretando como reflexo da sociedade ou apenas da natureza (OLIVEIRA, 2008).

Os países tropicais são os mais atingidos em função de suas características ambientais, climáticas e sociais. Essa doença caracteriza-se por ser febril aguda, cujo agente etiológico é constituído por quatro sorotipos: DEN-1, 2, 3 e 4 até o presente momento. A transmissão 


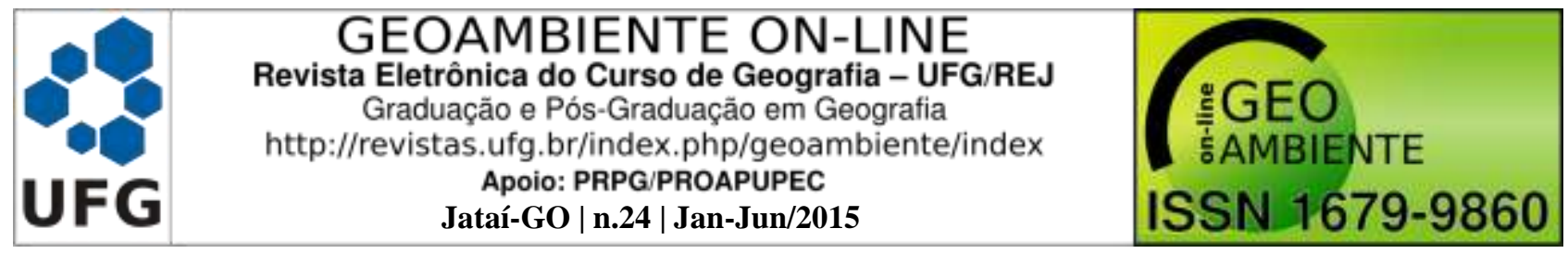

ocorre principalmente pela picada de mosquitos Aedes aegypti infectados, os quais possuem hábito domiciliar. Sua convivência com o homem é favorecida pela utilização de recipientes artificiais no desenvolvimento das formas imaturas, condição ecológica que torna esta espécie predominantemente urbana (FORATTINE, 2002). A imunidade em relação a Dengue se refere ao tipo de vírus que foi contraído, ou seja, para um individuo que nunca contraiu a doença, há a possibilidade de se contrair a Dengue por quatro vezes e até a forma mais grave da doença, a Dengue hemorrágica (COSTA, 2001).

O Aedes aegypti pode se alimentar de seivas de plantas, mas as fêmeas da espécie são hematófagas, isto é, alimentam-se de sangue também. Este comportamento faz com que ao ingerir o sangue infectado do hospedeiro, ela adquira o microrganismo que produz a doença. O ciclo de vida do mosquito apresenta quatro fases e dura em torno de 60 dias, sendo que a vida do vetor está estimada numa média de 30 dias, e a quantidade de ovos depositados, quando férteis estão entre 150 e 200 ovos. Na natureza, os ovos podem sobreviver até 450 dias fora d'agua (IOC/FIOCRUZ, 2014).

O clima quente e úmido da zona tropical reúne as condições ideais para proliferação do mosquito transmissor da Dengue, pois o vetor precisa de uma temperatura que varie entre $20^{\circ} \mathrm{C}$ e $46^{\circ} \mathrm{C}$ (COSTA, 2001). Com exceção da região Sul do Brasil, onde a temperatura média é baixa e os casos da doença são poucos, o restante do Brasil apresenta elevados índices da doença.

Outra característica destacada segundo Donalísio e Glasser (2002), é que as fêmeas do mosquito, infectadas e submetidas a temperaturas de aproximadamente $32^{\circ} \mathrm{C}$, teriam 2,64 vezes mais chances de completar o período de incubação extrínseco do que aquelas submetidas a temperaturas inferiores. Neste caso, fica provado que as áreas que mantém temperaturas mais elevadas são mais suscetíveis à presença e proliferação do mosquito Aedes aegypti.

A partir de uma análise dos indicadores climatológicos, pretende-se estabelecer se há correlação entre o alto índice de casos de Dengue no período de 2001 a 2010, analisando a sazonalidade e as médias de casos da doença, bem como os fatores geográficos podem interferir nessa concentração de casos na XVI RA de Jacarepaguá.

\section{MATERIAL E MÉTODOS}

O presente estudo está localizado no município do Rio de Janeiro na Área de planejamento 4 (AP 4), que é composta pela XVI Região Administrativa (RA) de Jacarepaguá 
e XXIV RA da Barra da Tijuca. O recorte espacial desta pesquisa, porém, ficou restrita somente a XVI RA de Jacarepaguá-RJ.

A XVI RA de Jacarepaguá engloba 10 bairros (Jacarepaguá, Anil, Gardênia Azul, Curicica, Freguesia, Pechincha, Taquara, Tanque, Praça Seca e Vila Valqueire) em uma área total de $126,61 \mathrm{~km}^{2}$.

Figura 1. Mapa das áreas de planejamento do município do Rio de Janeiro

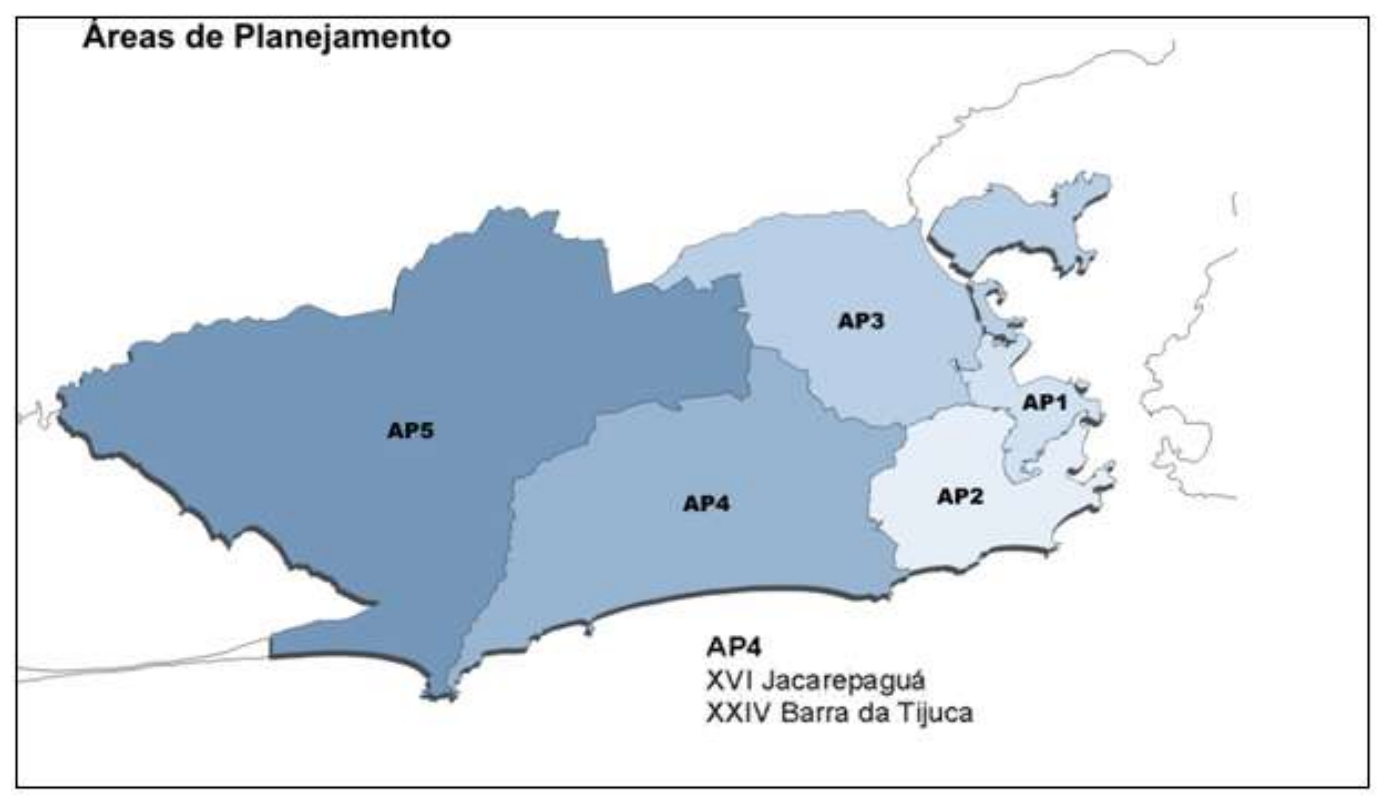

Fonte: elaborado pelos autores

No censo do IBGE de 2010, há o registro de 572030 habitantes, representando um crescimento de $22 \%$ em relação ao último levantamento de 2000 . A XVI representava $69 \%$ do contingente populacional em 2000 e $63 \%$ em 2010. Esse grande contingente populacional tem forte relação com a instalação das indústrias farmacêuticas na região e o atual investimento em obras de infraestrutura de transportes e de instalações esportivas para as Olimpíadas de 2016.

A XVI RA de Jacarepaguá possui um clima típico de região litorânea tropical, influenciada pela sua localização geográfica (latitude e longitude), proximidade com o mar, topografia local, natureza da cobertura vegetal e ação da circulação local, como as brisas marítimas e terrestres. O clima dessa região é tropical chuvoso megatérmico, caracterizandose por um verão úmido e um inverno seco. Os estudos de Laeta e Brandão (2008) demostram que o crescimento populacional está associado ao aumento do clima local. A crescente impermeabilização do solo, como também a retirada da cobertura vegetal vem trazendo um 


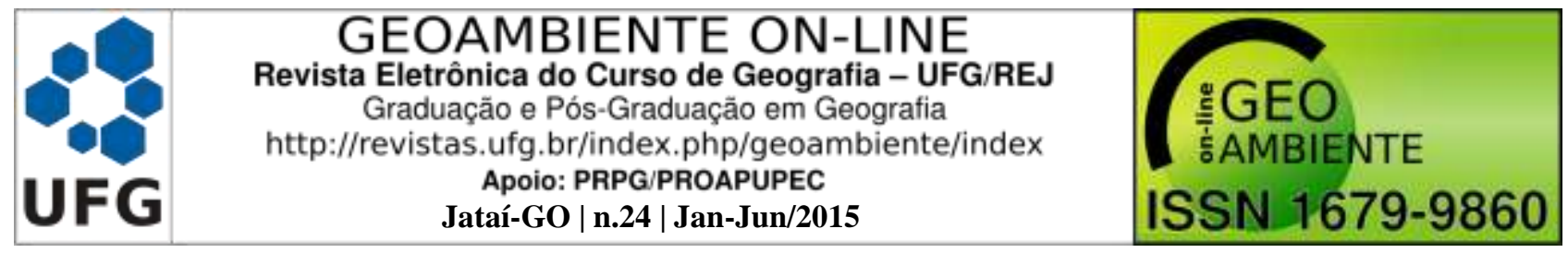

aumento da temperatura máxima e uma diminuição da temperatura mínima. Esta conjuntura corrobora com os estudos de Donalísio e Glasser (2002) que demonstra que as temperaturas mais elevadas são mais suscetíveis à presença e proliferação do mosquito Aedes aegypti.

As mais altas temperaturas e os valores mais altos de pluviosidade ocorrem no período de verão/outono (dezembro a abril) e os menores valores ocorrem no inverno (maio a agosto).

Os aspectos geográficos dificultaram por muito tempo a ocupação desta área da cidade, devido ao difícil acesso. A inserção da população neste espaço deu-se mediante a entrada entre os dois maciços, o da Tijuca e o da Pedra Branca, sendo configurado por um ambiente rural com chácaras e sítios em sua grande maioria (IPP, 2005). Somente em meados do século XX que esta área foi anexada ao território da cidade, em função do surgimento de novas vias rodoviárias, o que propiciou um processo acelerado de ocupação, devido ao seguimento do eixo litorâneo que vinha da zona sul, constituindo um dos mais valorizados setores imobiliários da cidade, onde se formaram dois vetores residenciais que comandaram o crescimento urbano da área, Jacarepaguá como o mais antigo e o novo, pela Barra da Tijuca (IPP, 2005).

Os bairros de Jacarepaguá e Barra da Tijuca estão crescendo em um ritmo muito acelerado, fazendo com que as áreas verdes ainda existentes sejam cada vez mais pressionadas e incorporando nesses locais um grande número de obras devido a essa nova realidade. Toda essa conjuntura na região aliada as características climáticas favorecem a disseminação do Aedes aegypti.

\section{METODOLOGIA}

Este artigo visa comparar o clima e a sua influência sobre a dengue na XVI Região Administrativa de Jacarepaguá-RJ.

A aquisição dos dados da Dengue foi obtida através da Secretaria da Saúde do município e do Ministério da Saúde, onde os mesmos foram compilados no banco de dados em uma tabela no formato xls (Excel), e posteriormente transformados e comparados por meio de mapas, gráficos e tabelas com dados de chuva e temperatura.

Os dados de chuva das estações do Rio de Janeiro foram adquiridos pelo Sistema Alerta Rio, da Prefeitura do Rio de Janeiro (ALERTA RIO) e os dados de temperatura do ar pelo Instituto Nacional de Meteorologia (INMET), contendo uma série de 10 anos de dados no período de 2001 até 2010. 


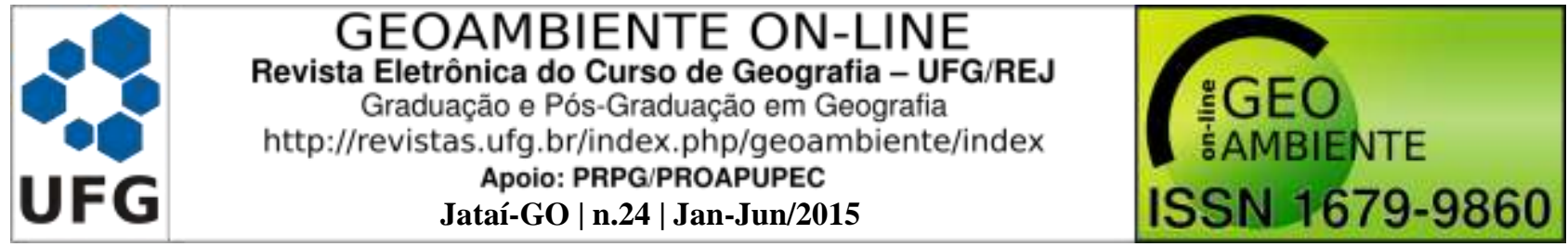

As estações meteorológicas utilizadas foram a pluviométrica de Jacarepaguá/Tanque, localizada na latitude: $-22,91$ e longitude $-43,36$, de procedência do Alerta Rio e a estação A654 Rio-Jacarepaguá (INMET), cuja localização é latitude -22,99 e longitude 43,37.

A correlação de Pearson foi utilizada para estabelecer o grau de relação entre a taxa de incidência da Dengue e as variáveis climatológicas. Neste caso o quão bem uma equação linear descreve ou explica a relação entre ambas.

O estudo também utilizou o conceito de time lag de Depradine e Lovell (2004) porque a sua utilização permite investigar os fenômenos resultantes das interações com o ambiente num determinado espaço e tempo, uma vez que os clássicos procedimentos de correlação simultânea para identificar relações entre casos de Dengue e os elementos climáticos fornecem correlações fracas de maneira geral, embora estatisticamente significantes, pois seria necessário considerar mais um intervalo de tempo para a ocorrência de associações mais explícitas. Esse intervalo seria condicionado por fatores como: período de desenvolvimento embrionário do mosquito, tempo de eclosão de larvas, período de incubação extrínseco e intrínseco do vírus.

\section{RESULTADOS E DISCUSSÕES}

A evolução dos casos notificados de Dengue na Cidade do Rio de Janeiro e na AP4 como um todo pode ser observada na Figura 2, que traz uma breve evolução histórica de 2001 a 2010, na qual se percebe quatro anos com notificações acima de 10 mil casos, em 2001, 2002, 2007 e 2008, e dois anos com notificações acima de 100 mil casos, 2002 com 145.779 notificações e 2008 com 120.921 notificações, o que nos mostra um intervalo de 6 anos entre os dois maiores picos.

Identificado os cinco anos com maior número de casos notificados de Dengue para o Rio de Janeiro no período analisado, é pertinente analisarmos a média da distribuição mensal dos casos de Dengue para a área de estudo, salientando a taxa de incidência de Dengue por 100 mil habitantes, na qual, segundo o Ministério da Saúde, 300 casos por 100 mil habitantes, é considerada epidemia. A figura 3 demonstra uma sazonalidade a partir de Dezembro a Maio, com a frequência dos picos significativos, ou seja, acima dos 300 casos por $100 \mathrm{mil} / \mathrm{hab}$. entre Janeiro e Abril na região. 
Figura 2. Gráfico Evolução dos casos Notificados de Dengue 2001 a 2010, na Cidade do Rio de Janeiro e na Área de Planejamento 4.

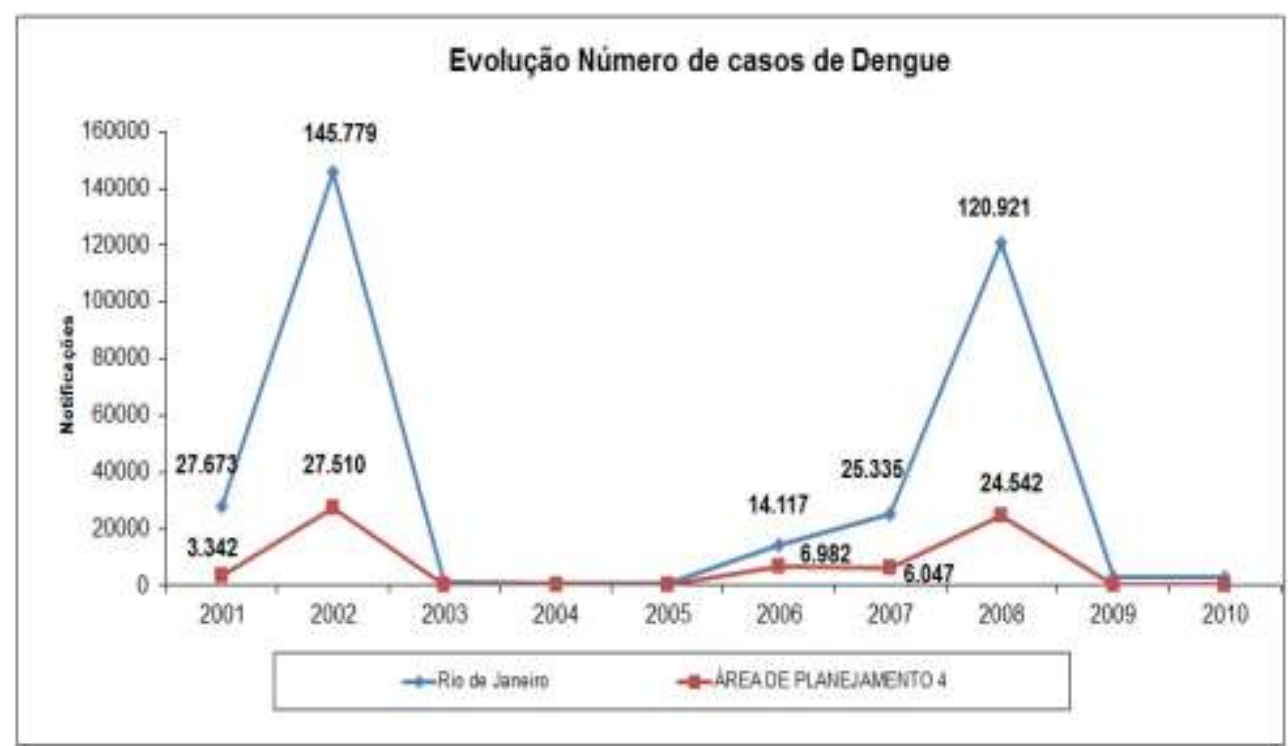

Base de dados: SMS/RJ 2012. Elaborado pelos autores

Figura 3. Gráfico da Incidência de Dengue para os anos com alto índice da doença (2001/2002/2006/2007 e 2008), para a XVI RA de Jacarepaguá.

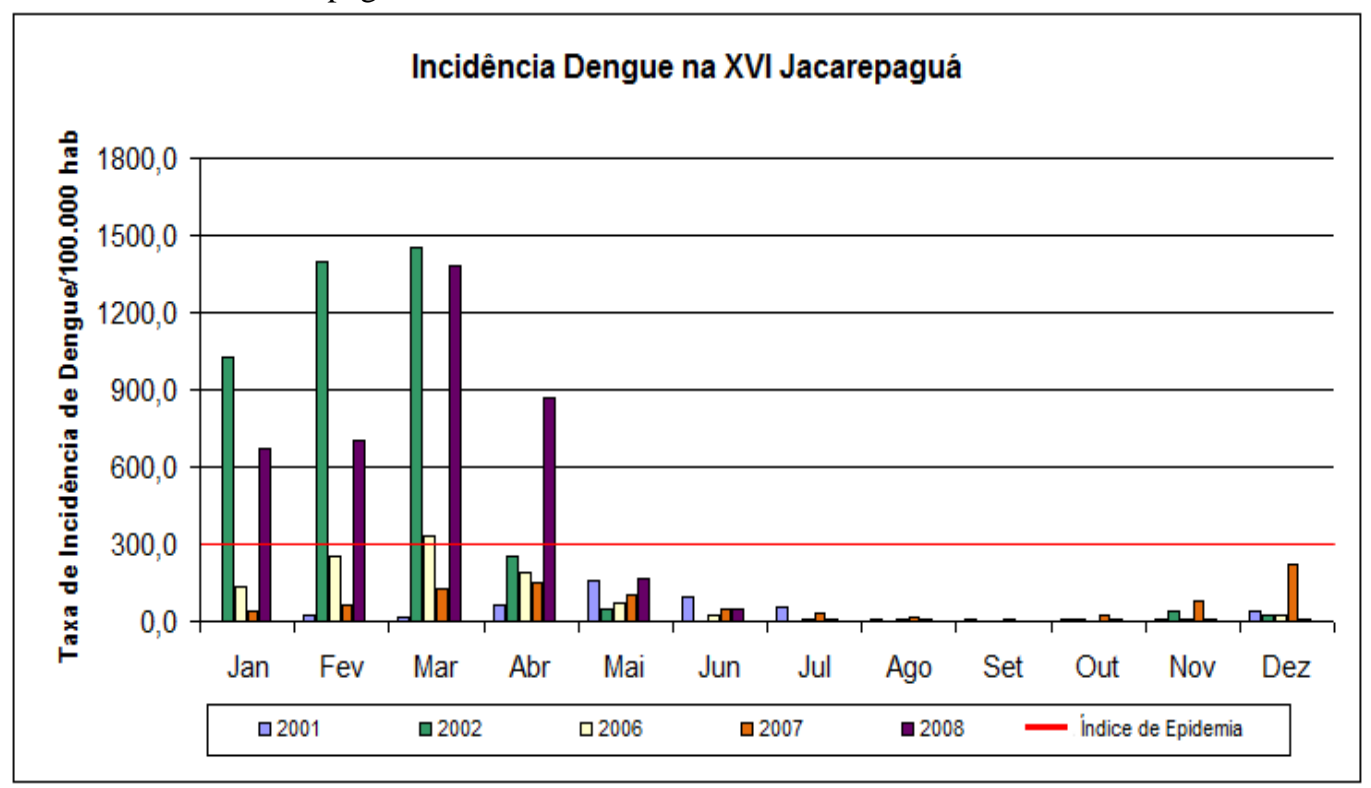

Base de dados: SMS/RJ 2012. Elaborado pelos autores

A sazonalidade observada na distribuição da Dengue na XVI RA, isto é, a concentração dos casos de Dezembro a Maio, que consideraremos como Verão e Outono neste estudo, nos mostram o comportamento ao longo dos anos de 2001 a 2010, nos quais, temos as maiores incidência de 704,3 casos por 100 mil habitantes em 2002 e 669,1 casos por 100 mil habitantes em 2008, salientando que temos números significativos para 2001, 2002, 2006 e 


\section{GEOAMBIENTE ON-LINE}

Revista Eletrônica do Curso de Geografia - UFG/REJ

Graduaçăo e Pós-Graduação em Geografia

http://revistas.ufg.br/index.php/geoambiente/index

Apoio: PRPG/PROAPUPEC

Jataí-GO | n.24 | Jan-Jun/2015

气̆GEO

¿̇AMBIENTE

ISSN 1679-9860

2007. Em contra partida de cinco anos com índices abaixo de 10 casos por 100 mil habitantes

(Figura 4) tivemos em uma década 50\% dos anos com números significativos de índices de incidência de Dengue na XVI RA de Jacarepaguá e 20\% dos anos com índices epidêmicos da Dengue.

Figura 4. Gráfico da média da incidência de Dengue, para os meses de Dezembro a Maio de 2001 a 2010, na XVI RA de Jacarepaguá.

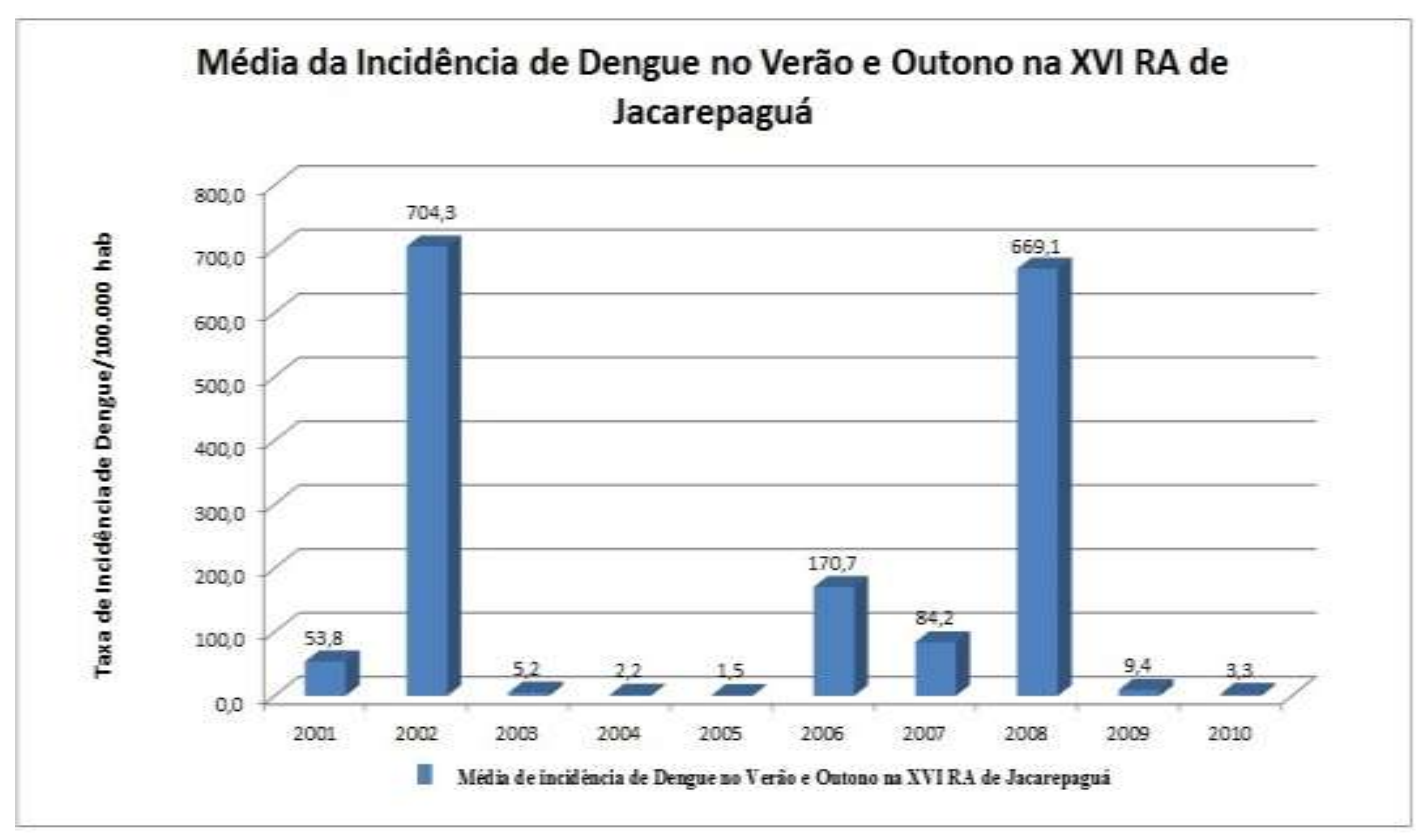

Fonte: SMS/RJ 2012

Observamos que o aumento do número da incidência de Dengue, isto é, os anos com maior pico não apresentaram um grau de correlação tão significativo com as variáveis climáticas, mas em geral nos mostraram uma sazonalidade bem definida, isto é, apresentaram um grau de correlação com o período do verão e outono de 2001 a 2010, onde a correlação (positiva) da Dengue com a temperatura foi de 0,79 (Figura 5), sendo considerada moderada. Em contra partida, a pluviosidade apresentou um grau de correlação (positiva) fraca com 0,48 (Figura 6). 
Figura 5. Correlação de Pearson para incidência de Dengue e temperatura no período de Dezembro a Maio (Verão/Outono) de 2001 a 2010, para área de Jacarepaguá.

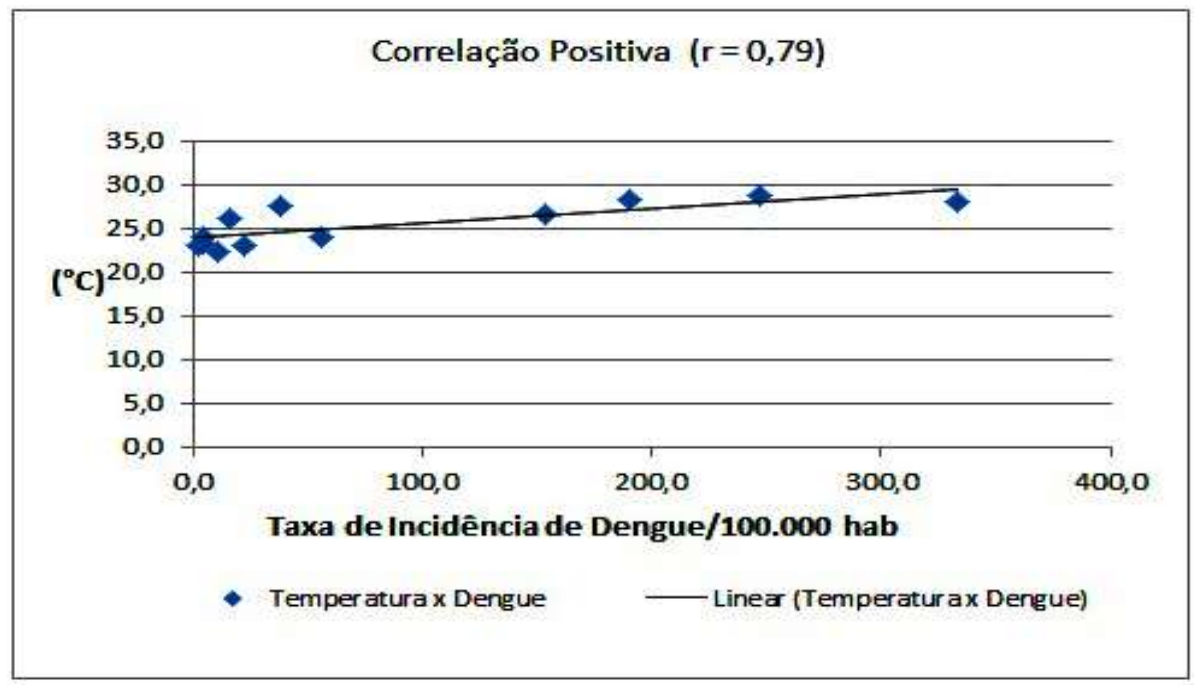

Base de dados: SMS/RJ, INMET \& Alerta Rio 2012.

Figura 6. Correlação de Pearson para incidência de Dengue e pluviosidade no período de Dezembro a Maio (Verão/Outono) de 2001 a 2010, para área de Jacarepaguá.

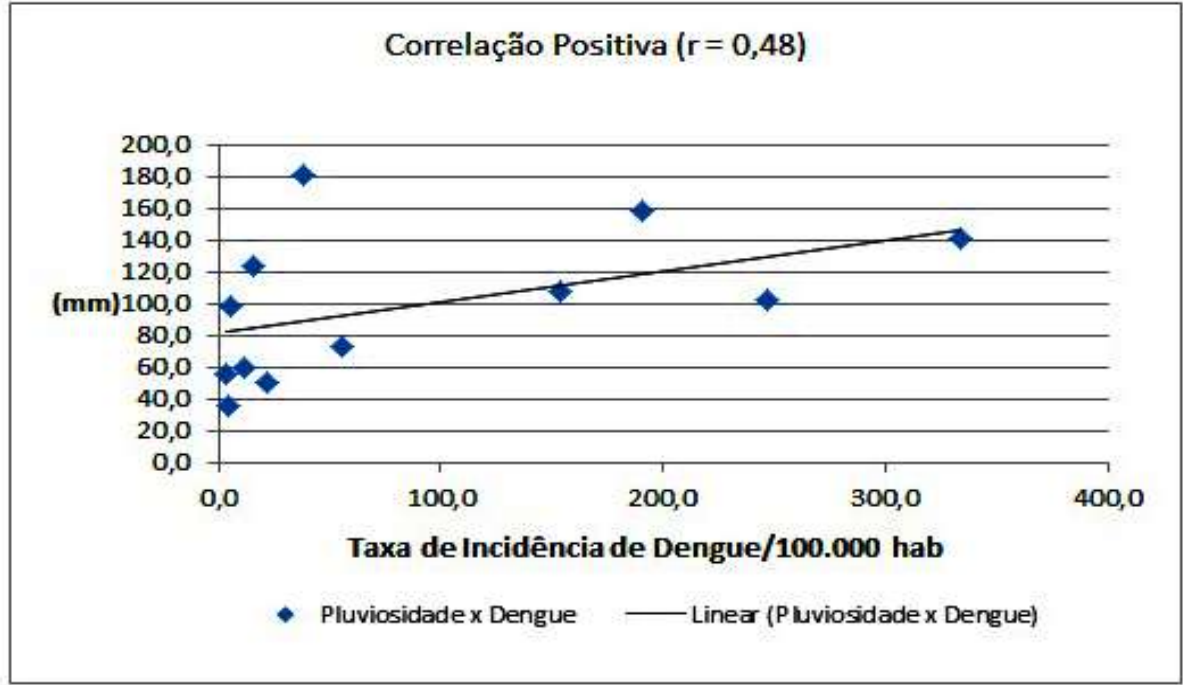

Base de dados: SMS/RJ, INMET \& Alerta Rio 2012.

A análise da correlação nos mostra que devemos ter outro olhar, ou seja, sabendo-se que a vida do vetor dura em torno de 60 dias e a fase inicial do mosquito enquanto embrião/larva, leva em torno de 20 a 30 dias, há necessidade de relevar o conceito de time lag, ou seja, avaliar a correlação através das condições climáticas do mês anterior em relação ao mês subsequente com a Dengue, na qual observamos uma correlação superior a estabelecida anteriormente, com 0,89 (Figura 7) em relação à temperatura de 0,66 com a pluviosidade (Figura 8), o que nos mostra a relação intrínseca da doença com a sazonalidade, 
mas que não são suficientes para explicar os anos com os altos picos de Dengue para área em análise, que em suma detém condições mais favoráveis para a disseminação do vetor e a ocorrência de epidemias ao longo dos anos.

Figura 7. Correlação de Pearson para incidência de Dengue e temperatura no período de Dezembro a Maio (Verão/Outono) de 2001 a 2010, para área de Jacarepaguá.

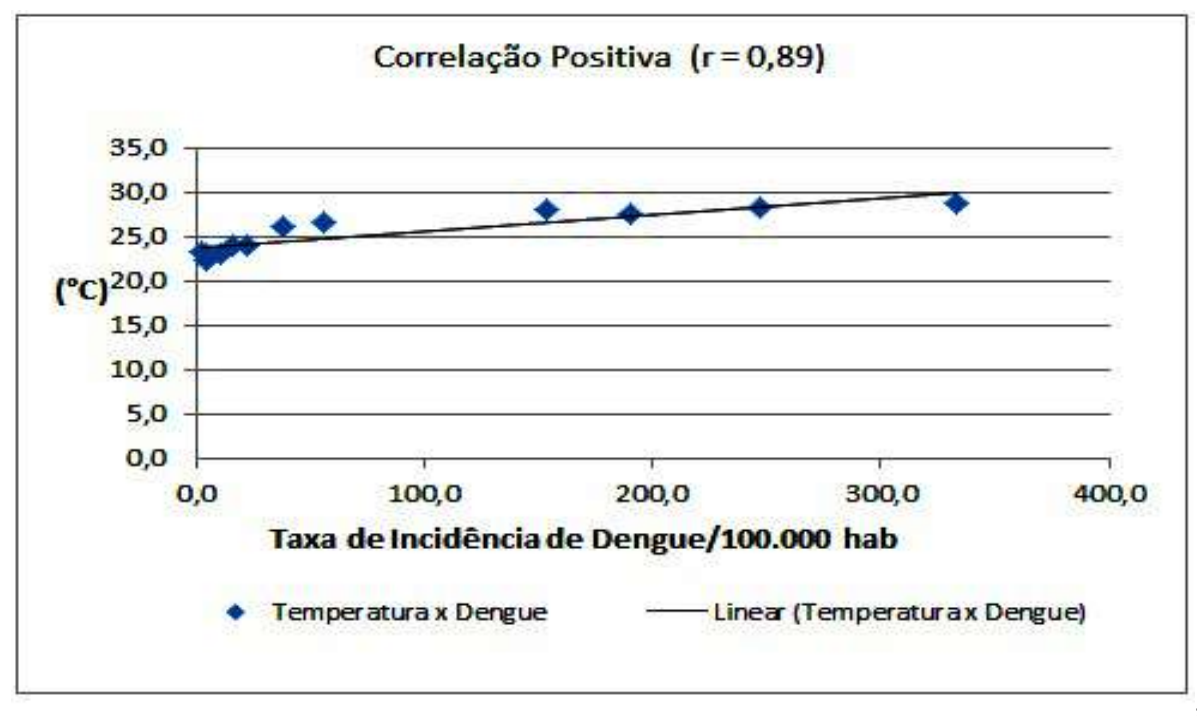

Base de dados: SMS/RJ, INMET \& Alerta Rio 2012.

Figura 8. Correlação de Pearson para incidência de Dengue e temperatura no período de Dezembro a Maio (Verão/Outono) de 2001 a 2010, para área de Jacarepaguá.

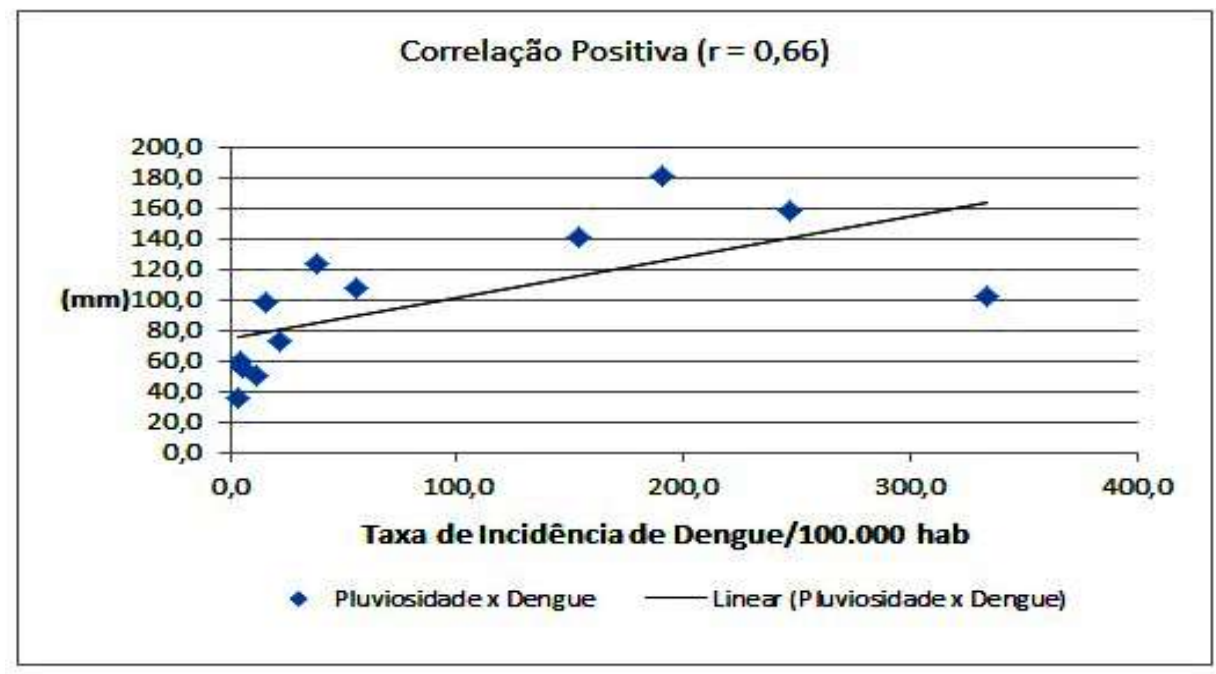

Base de dados: SMS/RJ, INMET \& Alerta Rio 2012.

Para tentar explicar as epidemias de dengue também é importante avaliar o tipo de vírus que circulou nesses períodos, neste sentido, segundo Medronho (2009) a partir da análise dos resultados do monitoramento da circulação viral no ano de 2008 no estado do Rio 


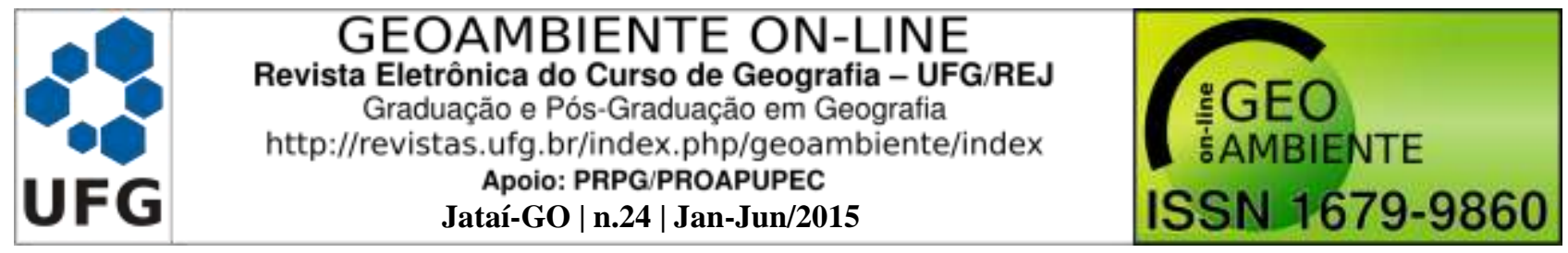

de Janeiro, o sorotipo 2 do vírus da Dengue circulou por todos os municípios,sendo que a predominância deste sorotipo no estado foi de $86 \%$. Esta constatação, associada à epidemia de 2001/2002, que teve a predominância do sorotipo 3, talvez explique em parte a gravidade da epidemia de 2007/2008 e um maior número de ocorrências na população jovem, principalmente entre as crianças, pois são pessoas que nasceram após a grande epidemia do sorotipo 2, ocorrida em 1990/1991 no estado do Rio de Janeiro. Portanto, muitas dessas pessoas estavam suscetíveis ao sorotipo 2 por terem nascido após esta epidemia, mas poderiam estar imunizadas com o sorotipo 3, que circulou em 2001/2002. Medronho (2009) chama atenção para a gravidade da epidemia de 2008, pois atingiu um grande número de crianças no Brasil como um todo com um aumento da forma mais grave da doença, uma vez que indivíduos que adquiriram imunidade de um tipo de sorotipo da Dengue passaram a ter mais chances de contrair a forma mais aguda da doença como a Dengue hemorrágica através de uma nova infecção por outro vírus da Dengue.

Como podemos perceber há inúmeros fatores que podem e devem ser considerados para a ocorrência da Dengue e epidemias. Constatamos que a área em estudo apresenta condições climáticas propícias para o desenvolvimento do mosquito, uma vez que a pluviosidade e temperatura mantêm condições favoráveis o ano todo, principalmente no verão e no outono devido às altas temperaturas e chuvas, se configurando assim, um ambiente de difícil controle da doença.

As condições climáticas da XVI RA de Jacarepaguá se assemelham com outras regiões do município do Rio de Janeiro, mas o número elevado de Dengue nestas áreas requer um olhar sobre o espaço geográfico, onde devemos levar em conta tanto os fatores naturais como sociais que em conjunto possam lançar uma luz sobre o quadro que se configura para a área em estudo. Neste sentido o crescimento urbano da área tem que ser avaliado como mais um fator de grande importância na disseminação da doença na região.

\section{CONSIDERAÇÕES FINAIS}

Aos olhos da Geografia é necessária a indagação, compreensão e explicação dos processos de produção espacial e como essa produção desigual afeta de forma diferenciada as pessoas. Para a explicação da Dengue ainda se privilegiam alguns aspectos do "meio físico" ou aspectos "ecológicos”, esquecendo-se que o espaço geográfico é produzido pela sociedade e que esses aspectos sócio espaciais são fundamentais para se entender as doenças no âmbito espacial da sociedade. 


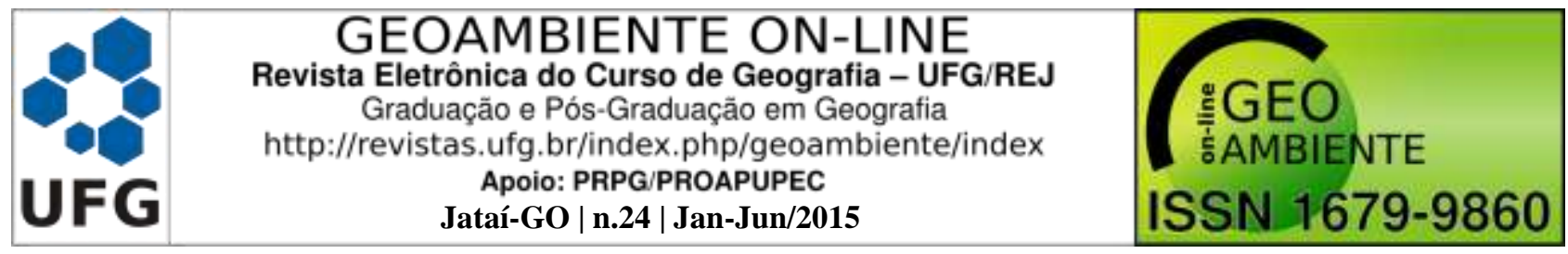

A partir da análise geográfica estabelecida no estudo, observamos que a correlação entre as variáveis climáticas e a incidência de dengue na XVI RA de Jacarepaguá não é tão pronunciada, mas nos mostra que a sazonalidade é bem definida, isto é, que a concentração dos casos, ficou evidenciada do verão até o outono.

A correlação das variáveis climáticas com a incidência de dengue não explicaram porque esta área detém em média o maior número de casos de Dengue na cidade do Rio de Janeiro, apresentando anos com alarmantes índices epidêmicos. Os aspectos geográficos que compõem o relevo e, por conseguinte o clima da área analisada é propicio a incidência de Dengue, mas há o agravante dos aspectos urbanos deficitários como falta de saneamento básico, coleta de lixo e abastecimento, que não acompanham o crescimento populacional e a expansão urbana na zona oeste da cidade, acima da média para a cidade do Rio de Janeiro. Aliado a todos esses fatores soma-se a mutabilidade do vírus da dengue que de tempos em tempos adquire uma nova forma e se torna mais adaptado ao meio urbano. A presença de novos vírus impossibilita a criação de vacinas e aumenta as chances de casos mais graves, que por sua vez também corroboram com o prolongamento da epidemia uma vez que, por quando mais tempo o indivíduo fica doente por mais tempo ele se torna disseminador da doença.

Os novos vírus acometem quase todo o Brasil, mas no Rio de Janeiro e mais especificamente em Jacarepaguá estes encontram campo fértil para sua disseminação, uma vez que o clima e o meio urbano do entorno são favoráveis

\section{REFERÊNCIAS}

ALERTA RIO. Sistema Alerta Rio da Prefeitura do Rio de Janeiro. Disponível em: http://alertario.rio.rj.gov.br/. Acesso em: 09/11/2014.

COSTA, M. A. R. A Ocorrência do Aedes aegypti na Região Noroeste do Paraná: um estudo sobre a epidemia da dengue em Paranavaí - 1999, na perspectiva da Geografia Médica. 2001. 214 p. Dissertação (Mestrado em Institucional em Geografia). Universidade Estadual Paulista - Faculdade Estadual de Educação Ciências e Letras de Paranavaí, Presidente Prudente.

DEPRADINE ;C.A, LOVELL E.H. Climatological variables and the incidence of dengue fever in Barbados. Int J Environ Health Res.n:14; 429-41. 2004.

DONALÍSIO, M. R; GLASSER, C.M. Vigilância entomológica e controle de vetores do dengue. Revista Brasileira de Epidemiologia. São Paulo, v. 5 n.3. 2002. 
http://www.ensp.fiocruz.br/portal-ensp/informe/site/materia/detalhe/24332.Acesso 24/03/2014.

FUNASA- Fundação Nacional de Saúde. Dengue: Instruções para pessoal de combate ao vetor. Manual de normas e técnicas. 3. Ed. Brasília (DF), 2001, 84 p.

FORATTINI,O.P. Culicidologia Médica: Identificação, Biologia e Epidemiologia. 2ed. São Paulo: Universidade de São Paulo. 2002. 860p.

IBGE. INSTITUTO BRASILEIRO DE GEOGRAFIA E ESTATÍSTICA. Disponível em: http://www.ibge.gov.br/home/ Acesso em: 05/12/2014.

INSTITUTO PEREIRA PASSOS. PREFEITURA DA CIDADE DO RIO DE JANEIRO. Plano Diretor Decenal de 1992: Subsídios para sua revisão - 2005. Rio de Janeiro: IPP, 2005. INMET. INSTITUTO NACIONAL DE METEOROLOGIA. Disponível em: http://www.inmet.gov.br/portal/. Acesso em:22/09/2014.

KHORMI, H. M. et al. Modeling spatio-temporal risk changes in the incidence of dengue fever in Saudi Arabia: a geographical information system case study. Geospatial Health, 6 (1), 77-84, 2011.

LAETA, T.; BRANDÃO, A.M.P.M. Evolução urbana e prováveis alterações climáticas em Jacarepaguá/RJ. In: VIII SIMPÓSIO BRASILEIRO DE CLIMATOLOGIA GEOGRÁFICA. 2008, Alto do Caparaó-MG. Anais... Alto do Caparaó: Universidade Federal de Uberlândia, 2008.

MEDRONHO, R.A. Dengue: aumento da gravidade e deslocamento para a infância. Cadernos Saúde Coletiva (UFRJ), v. 17, p. 301-304, 2009.

MENDONÇA, F. A. et al. Saúde pública, urbanização e dengue no Brasil. Sociedade \& Natureza, Uberlândia, v. 21, n. 3, p. 257-269, 2009.

MONDINI, A.et al. Análise espacial da transmissão de dengue em cidade de porte médio do interior paulista Spatial analysis of dengue transmission in a medium-sized city in Brazil. Revista Saúde Pública, 39(3), 444-451, 2005.

OLIVEIRA, E. C. Verificação da influência da temperatura do ar e chuva do Distrito Federal na Dengue./ Brasília: ICHUnB, 2008, 95.p. Dissertação de Mestrado - Universidade de Brasília, ICH.

SANTOS, M. Por uma outra globalização: do pensamento único à consciência universal. São Paulo : Record, 2003.174p. 


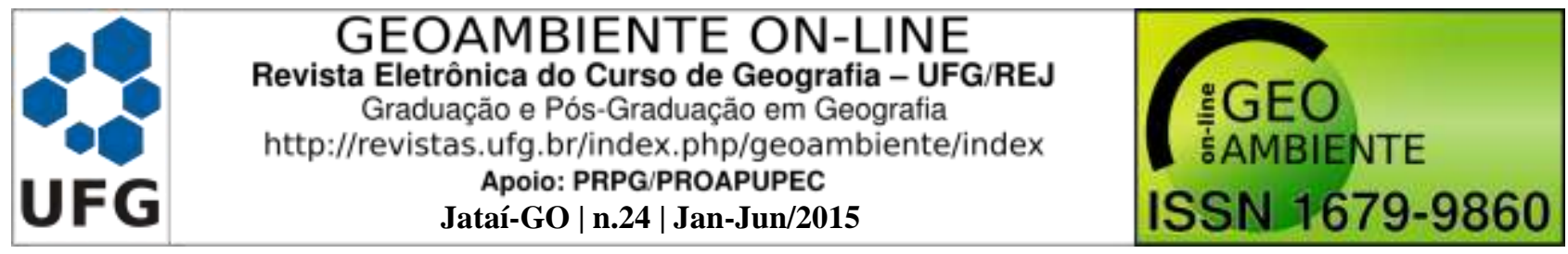

SILVA, J. S et al. Influencia do clima urbano na proliferação do mosquito Aedes aegypti em Jataí (GO) na perspectiva da geografia médica. Revista Hygeia, v. 2, n.5, p.33-49, 2007.

SMS. SECRETARIA MUNICIPAL DE SAÚDE. Disponível em: http://www.rio.rj.gov.br/web/sms. Acesso em: 25/08/2014.

TEIXEIRA, M. G. et al. Epidemiologia e medidas de prevenção do dengue. Informe Epidemiológico do SUS, v.8, n.4, p.5-33, 1999. 